\title{
Influence of activator type on reaction kinetics, setting time, and compressive strength of alkali-activated mineral wools
}

\author{
J. Yliniemi ${ }^{1} \cdot$ B. Walkley ${ }^{2,3} \cdot$ J. L. Provis ${ }^{2} \cdot$ P. Kinnunen ${ }^{1} \cdot$ M. Illikainen $^{1}$
}

Received: 28 June 2019 / Accepted: 27 March 2020 / Published online: 8 April 2020

(c) The Author(s) 2020

\begin{abstract}
Alkali activation is a promising utilisation route for mineral wool wastes, due to suitable chemical composition, high reactivity, and surface area. One key factor in the development of alkali-activated binders is the selection of the suitable alkali activator. Here, the effect of sodium hydroxide, sodium silicate, sodium aluminate, and sodium carbonate solution on the alkali-activation kinetics of two main types of mineral wools, stone wool and glass wool, is investigated. Setting time and compressive strength development results are presented, which are explained and discussed in the context of isothermal calorimeter data obtained at temperature of $40{ }^{\circ} \mathrm{C}$. Sodium hydroxide and sodium silicate solutions provided fast reaction with both mineral wools, evidenced by high heat release, high early strength, and fast setting. The reaction with sodium aluminate solution took several days to initiate, but it produced high compressive strength after 28 days of curing with both mineral wools. Glass wool reacted and hardened rapidly with sodium carbonate solution, but stone wool reacted slowly with sodium carbonate and exhibited a low extent of reaction, likely due to lower extent of reaction of stone wool under less alkaline conditions. These results show that mineral wool alkali activation kinetics and binder gel formation are controlled by the activator type and highlight the importance of choosing the most appropriate activator for each desired application.
\end{abstract}

Keywords Alkali-activated binders $\cdot$ Geopolymer $\cdot$ Isothermal calorimetry $\cdot$ Stone wool $\cdot$ Glass wool $\cdot$ Sustainability

\section{Introduction}

Alkali-activated binders based on industrial side streams can represent a viable and sustainable alternative to Portland cement in many applications [1]. Alkali-activated binders can be generated from a wide range of aluminosilicate precursors with differing availability, reactivity, and cost worldwide, with blast furnace slag and coal fly ash being the most common ones used [2]. The implementation of a new type of binder from a new type of precursor encounters many

J. Yliniemi

juho.yliniemi@oulu.fi

1 Fibre and Particle Engineering Research Unit, University of Oulu, P.O. Box 4300, 90014 Oulu, Finland

2 Department of Materials Science and Engineering, The University of Sheffield, Sir Robert Hadfield Building, Mappin St, Sheffield S1 3JD, UK

3 Department of Chemical and Biological Engineering, The University of Sheffield, Sir Robert Hadfield Building, Mappin St, Sheffield S1 3JD, UK technical and commercial challenges, including the need for careful control of formulation and curing [1,3].

There are some general requirements for all new sustainable construction binders. First, suitable raw materials (precursors and activators) should be locally available in order to minimise the costs and the environmental burden of material transportation. Moreover, the precursor must be sufficiently reactive under the preparation conditions and the chemical composition should promote the formation of strong and durable binder gels. Preferably, the precursor should have constant quality regarding its chemical composition and particle size distribution, thus eliminating extra processing steps in practical use.

Mineral wool wastes meet many of the above-mentioned requirements for alkali-activated binder precursors. Mineral wool waste is generated during construction and demolition $(C \& D)$ of buildings and also from mineral wool manufacturing. It is currently a largely unutilised mineral waste, with an annual production of 2.5 million tonne in the European Union alone [4]. The volume of mineral wool waste is expected to increase worldwide due to emerging energy efficiency in building design which will increase the amount 
of mineral wool used, but also as old mineral wool thermal insulation in buildings needs to be renew over time, it becomes spoiled, thus losing its durability and performance [5]. Mineral wool waste has high specific surface area, and it is X-ray amorphous, both of these factors increasing its reactivity under alkaline conditions $[6,7]$. Finally, as mineral wool is originally a product of an industrial process that depends on carefully designed chemical composition and fibre width, its quality is relatively constant with respect to location and time of production compared to many other industrial by-products such as coal fly ash.

The two main types of mineral wools, stone wool and glass wool, differ greatly in their chemical composition. The main components of typical stone wool are $\mathrm{SiO}_{2} 40-45$ mass $\%, \mathrm{Al}_{2} \mathrm{O}_{3} 16-18$ mass $\%, \mathrm{CaO} 16-18$ mass $\%$, and $\mathrm{MgO}$ 9-12 mass\%, representing quite a different composition from any other major alkali-activated binder precursors. The main components of glass wool are 60-65 mass\% $\mathrm{SiO}_{2}, 16$ mass $\% \mathrm{Na}_{2} \mathrm{O}$, and 7 mass $\% \mathrm{CaO}$, which is similar to everyday soda-lime glass. The above-mentioned oxides under alkali activation can promote the formation of binder gels such as calcium-(sodium-)aluminate-silicate-hydrates $(\mathrm{C}-(\mathrm{N}-) \mathrm{A}-\mathrm{S}-\mathrm{H})$, sodium-aluminate-silicate-hydrates $(\mathrm{N}-\mathrm{A}-\mathrm{S}-\mathrm{H})$, and layered double hydroxides (LDHs) that have been shown to give excellent mechanical strength and durability [2].

One key development step with each new precursor is a well-formulated mix design with particular consideration of the alkali activator. The alkali activator provides a high $\mathrm{pH}$ and largely controls precursor dissolution, hydration kinetics, and precipitation of reaction products, which again control the setting and development of compressive strength of the binder, which are critical parameters in their practical use. Here, the heat release profile during the setting and hardening becomes particularly useful as it is a sensitive measure of the kinetics of the reaction [8-11]. The most commonly used activators are sodium-based solutions, including silicates, hydroxides, sulphates, and carbonates. Additionally, a major part of the environmental footprint of an alkali-activated binder results from the production of the alkali activator [12], which further emphasises the importance of careful selection of the alkali activator.

For major alkali-activated binder precursors such as metakaolin, ground granulated blast furnace slag (GGBFS), and coal fly ash, the effect of activator has been studied widely over the past several decades [13]. To briefly summarise, silicate activators provide generally high strength and durable binders with slags, calcined clays, and fly ashes, whereas the use of hydroxide activators can generate valuable binders, but there are significant drawbacks in terms of strength development, durability, and/or workability. Carbonate and sulphate activators are much less studied, and strength development is generally insufficient for most applications [14, 15].

Furthermore, it has been shown that even a seemingly small difference in $\mathrm{MgO}$ (8-13 mass\%) or $\mathrm{Al}_{2} \mathrm{O}_{3}(7-17$ mass\%) content in GGBFS results in different reaction kinetics, degree of reaction, compressive strength, and porosity when activated with $\mathrm{NaOH}$ and sodium silicate activators $[16,17]$. This emphasises the fact that assumptions about the reactivity between an activator and precursor based on previous work may not be valid, even if similar precursors have been used. Currently, there are only three papers regarding alkali activation of mineral wools $[6,7,18]$, none of which have considered the effect of activator type on reaction kinetics and hardening.

Thus, there is a clear and important gap in the scientific literature regarding detailed assessment of the nature of the alkali activator on alkali activation reaction kinetics, setting time, and development of compressive strength of alkaliactivated mineral wools. Such investigation is presented in this paper, using sodium silicate, sodium hydroxide, sodium aluminate, and sodium carbonate solutions as activators for stone wool and glass wool.

\section{Materials and methods}

Mineral wool samples were collected from a mineral wool manufacturing line before the addition of organic resins or other additives, to eliminate any possible effect of those additives on the activation and hardening reactions. We chose to use generic terms 'mineral wool', 'stone wool', and 'glass wool' throughout the paper for simplicity, even though one could argue that these organic-free materials are in fact mineral fibres. The chemical compositions of the samples (Table 1) were determined using a $4 \mathrm{kV}$ wavelength-dispersive X-ray fluorescence (XRF) spectrometer (PANalytical AxiosmAX). XRF analyses were performed from fused samples: $1.5 \mathrm{~g}$ of sample was melted at $1150{ }^{\circ} \mathrm{C}$ with $7.5 \mathrm{~g}$ of X-ray Flux Type 66:34 (66 mass\% $\mathrm{Li}_{2} \mathrm{~B}_{4} \mathrm{O}_{7}$ and 34 mass\% $\mathrm{LiBO}_{2}$ ) to obtain melt-fused tablets. In addition to the major oxides given in Table 1, glass wool typically contains $\sim 2-4$ mass\% of $\mathrm{B}_{2} \mathrm{O}_{3}$ [7], which is not quantifiable using XRF. Moisture content and loss-on-ignition were measured with thermogravimetric analysis (TGA) at static air using Prepash Precisa Gravimetrics AG: 'prepASH automatic drying and ashing system'. The temperature program in TGA was $30 \mathrm{~min}$ ramp from 22 to $105^{\circ} \mathrm{C}$ with $4 \mathrm{~h}$ hold and then $2 \mathrm{~h}$ $30 \mathrm{~min}$ ramp to $525^{\circ} \mathrm{C}$ with $3 \mathrm{~h}$ hold. The negligible result for loss-on-ignition at $525{ }^{\circ} \mathrm{C}$ confirmed that the samples were free of organic additives.

Before alkali activation, the mineral wools were ground with a Germatec ball mill in a $10-\mathrm{L}$ milling chamber for 
Table 1 Major oxides, milled fibre dimensions, and surface area of the stone wool (SW) and glass wool $(\mathrm{GW})$ used in this study

\begin{tabular}{|c|c|c|}
\hline & Stone wool (SW) & Glass wool (GW) \\
\hline $\mathrm{SiO}_{2}$ mass $/ \%$ & 40.5 & 63.3 \\
\hline $\mathrm{Al}_{2} \mathrm{O}_{3}$ mass $/ \%$ & 16.0 & 1.5 \\
\hline $\mathrm{CaO}$ mass $/ \%$ & 18.3 & 8.2 \\
\hline $\mathrm{MgO}$ mass $/ \%$ & 11.9 & 3.1 \\
\hline $\mathrm{Fe}_{2} \mathrm{O}_{3}$ mass $/ \%$ & 6.7 & 0.5 \\
\hline $\mathrm{Na}_{2} \mathrm{O}$ mass $/ \%$ & 1.4 & 16.5 \\
\hline $\mathrm{K}_{2} \mathrm{O}$ mass $/ \%$ & 0.9 & 0.5 \\
\hline $\mathrm{TiO}_{2}$ mass $/ \%$ & 1.5 & 0.0 \\
\hline Moisture content mass $/ \%$ & 0.06 & 0.02 \\
\hline $\begin{array}{l}\text { Loss-on-ignition } 525^{\circ} \mathrm{C} \\
\text { mass } / \%\end{array}$ & 0.01 & 0.06 \\
\hline Average fibre length/ $\mu \mathrm{m}$ & 28 & 32 \\
\hline Average fibre width/ $\mu \mathrm{m}$ & 8 & 10 \\
\hline Surface area $/ \mathrm{cm}^{2} \mathrm{~g}^{-1}$ & $7241 \pm 18$ & $6528 \pm 22$ \\
\hline
\end{tabular}

three hours. Steel balls (150 pcs.) $25-40 \mathrm{~mm}$ in diameter were used.

The average lengths and widths of the fibres were analysed using a large tube flow fractionation method as described previously [19]. The camera resolution of large tube flow fractionation method is $6.4 \mu \mathrm{m}$ [19]; thus, the finest fraction of the milled mineral wool particles is not detected, which increases the measured average fibre length and width. Specific surface area measurement was based on the physical adsorption of gas molecules on a solid surface using a physisorption analyser (ASAP 2020, Micromeritics Instrument Corp.), and the results were reported in the form of a BET isotherm.

\section{Preparation of alkali activators}

$\mathrm{NaOH}$ solution $(\mathrm{NaOH})$ was prepared by mixing 20 mass- $\%$ reagent grade $\mathrm{NaOH}$ pellets [VWR Chemicals] and 80 mass-\% deionised water to give a $6.25 \mathrm{~mol} / \mathrm{L}$ solution.

Sodium silicate solution $\left(\mathrm{Na}_{2} \mathrm{O} \cdot 2 \mathrm{SiO}_{2}\right)$ with a $\mathrm{SiO}_{2} / \mathrm{Na}_{2} \mathrm{O}$ molar modulus (Ms) of 2.0 was prepared by mixing 87.6 mass-\% sodium silicate solution (Betol $50 \mathrm{~T}$ [Wöllner], 31.8 mass- $\% \mathrm{SiO}_{2}, 12.7$ mass- $\% \mathrm{Na}_{2} \mathrm{O}$, and 55.5 mass- $\%$ $\mathrm{H}_{2} \mathrm{O}$ ) with 9.6 mass- $\%$ deionised water and 2.8 mass- $\%$ reagent grade $\mathrm{NaOH}$ pellets [VWR Chemicals]. The final $\mathrm{Na}_{2} \mathrm{O} \cdot 2 \mathrm{SiO}_{2}$ solution contained 24.5 mass $-\% \mathrm{SiO}_{2}, 12.3$ mass- $\% \mathrm{Na}_{2} \mathrm{O}$, and 63.3 mass- $\% \mathrm{H}_{2} \mathrm{O}$.

Sodium aluminate solution $\left(2 \mathrm{Na}_{2} \mathrm{O} \cdot \mathrm{Al}_{2} \mathrm{O}_{3}\right)$ was prepared by mixing 5.1 mass- $\%$ of reagent grade $\mathrm{NaOH}$ pellets [VWR Chemicals] with 71.2 mass- $\%$ of deionised water and then adding 23.7 mass- $\%$ of anhydrous sodium aluminate powder $\left(\mathrm{NaAlO}_{2}\right)$ [Sigma-Aldrich].

$\mathrm{Na}_{2} \mathrm{CO}_{3}$ solution $\left(\mathrm{Na}_{2} \mathrm{CO}_{3}\right)$ was prepared by mixing 25.9 mass- $\%$ anhydrous sodium carbonate powder [SigmaAldrich] with 74.1 mass-\% of deionised water.

\section{Preparation of alkali-activated samples}

Milled mineral wool was added continuously into the alkali activator according to the amounts outlined in Table 2 . Mixing was done with a high shear mixer [RW20, IKA Labortechnik] at $800 \mathrm{rpm}$ with 5-min mixing time. For compressive strength measurements, sample pastes were cast into $2 \times 2 \times 8 \mathrm{~cm}$ metal moulds. Moulds were vibrated to remove entrained air bubbles, sealed with plastic to prevent water evaporation, and put into a $40{ }^{\circ} \mathrm{C}$ curing chamber. Samples were demoulded after curing for one day and kept sealed at $40{ }^{\circ} \mathrm{C}$ until compressive strength measurement.

Table 2 Mix designs of the alkali-activated samples

\begin{tabular}{|c|c|c|c|c|c|c|c|}
\hline Sample name & $\begin{array}{l}\text { Stone wool } \\
\text { mass } / \%\end{array}$ & $\begin{array}{l}\text { Glass wool } \\
\text { mass } / \%\end{array}$ & $\mathrm{NaOH}$ mass $/ \%$ & $\begin{array}{l}\mathrm{Na}_{2} \mathrm{O} \cdot 2 \mathrm{SiO}_{2} \\
\text { mass } / \%\end{array}$ & $\begin{array}{l}2 \mathrm{Na}_{2} \mathrm{O} \cdot \mathrm{Al}_{2} \mathrm{O}_{3} \\
\text { mass } / \%\end{array}$ & $\mathrm{Na}_{2} \mathrm{CO}_{3}$ mass $/ \%$ & $\begin{array}{l}\text { Water-to- } \\
\text { binder*/mass } \\
\text { ratio }\end{array}$ \\
\hline SW_NaOH & 67.4 & & 32.6 & & & & 0.35 \\
\hline $\mathrm{SW} \_\mathrm{Na}_{2} \mathrm{O} \cdot 2 \mathrm{SiO}_{2}$ & 59.0 & & & 41.0 & & & 0.31 \\
\hline $\mathrm{SW} \_2 \mathrm{Na}_{2} \mathrm{O} \cdot \mathrm{Al}_{2} \mathrm{O}_{3}$ & 63.9 & & & & 36.1 & & 0.35 \\
\hline $\mathrm{SW} \_\mathrm{Na}_{2} \mathrm{CO}_{3}$ & 65.3 & & & & & 34.7 & 0.35 \\
\hline GW_NaOH & & 67.4 & 32.6 & & & & 0.35 \\
\hline $\mathrm{GW} \_\mathrm{Na}_{2} \mathrm{O} \cdot 2 \mathrm{SiO}_{2}$ & & 59.0 & & 41.0 & & & 0.31 \\
\hline $\mathrm{GW} \_2 \mathrm{Na}_{2} \mathrm{O} \cdot \mathrm{Al}_{2} \mathrm{O}_{3}$ & & 63.9 & & & 36.1 & & 0.35 \\
\hline $\mathrm{GW} \_\mathrm{Na}_{2} \mathrm{CO}_{3}$ & & 65.3 & & & & 34.7 & 0.35 \\
\hline
\end{tabular}

*Water-to-binder ratio. Binder includes mineral wool and all the other components in alkali activator except water 


\section{Fresh and hardened state properties of pastes}

For fresh pastes, isothermal calorimetry experiments were conducted using a TAM Air isothermal calorimeter at a base temperature of $40 \pm 0.02{ }^{\circ} \mathrm{C}$. The fresh paste was prepared as explained above, weighed into an ampoule, and immediately placed in the calorimeter to record heat flow. All results were normalised by the total mass of paste. An equal amount of water as present in the paste samples was used as a reference sample for each measurement.

Initial and final setting times were determined with a Vicat apparatus (Vicatronic Matest) by taking the sample out of the curing chamber $\left(40^{\circ} \mathrm{C}\right)$ at fixed intervals and then putting the sample back into the curing chamber after each measurement. The interval used depended on the predetermined final setting time.

The compressive strengths of each mix were determined on 2-4 replicates using a Zwick/Roell Z100 testing machines with loading rate $2.4 \mathrm{kN} / \mathrm{s}$ at room temperature $\left(22 \pm 2{ }^{\circ} \mathrm{C}\right)$ and $35 \pm 5 \%$ relative humidity.

\section{Results and discussion}

In this section, first setting time and compressive strength development results are presented, which are then explained and discussed in the context of isothermal calorimeter results.

\section{a. Setting time}

The activator type has a large effect on the setting times determined for both mineral wools (Table 3). The fastest setting was measured for stone wool activated by $\mathrm{NaOH}$ solution, for which the final setting was identified after $3 \mathrm{~h}$ of curing. For $\mathrm{Na}_{2} \mathrm{O} \cdot 2 \mathrm{SiO}_{2}$-activated stone wool, the final setting time was slightly longer (4 h $10 \mathrm{~min}$ ) compared to

Table 3 Setting times of alkali-activated mineral wool samples at $40{ }^{\circ} \mathrm{C}$

\begin{tabular}{lll}
\hline Sample name & Initial setting time/h & $\begin{array}{l}\text { Final } \\
\text { setting } \\
\text { time/h }\end{array}$ \\
\hline $\mathrm{SW} \_\mathrm{NaOH}$ & 2.5 & 3.17 \\
$\mathrm{SW} \mathrm{Na}_{2} \mathrm{O} \cdot 2 \mathrm{SiO}_{2}$ & 3.17 & 4.17 \\
$\mathrm{SW} \_2 \mathrm{Na}_{2} \mathrm{O} \cdot \mathrm{Al}_{2} \mathrm{O}_{3}$ & 8.17 & 11.83 \\
$\mathrm{SW} \_\mathrm{Na}_{2} \mathrm{CO}_{3}$ & 28 & 30 \\
$\mathrm{GW} \_\mathrm{NaOH}_{\mathrm{O}}$ & 8 & 10.5 \\
$\mathrm{GW} \mathrm{Na}_{2} \mathrm{O} \cdot 2 \mathrm{SiO}_{2}$ & 4.17 & 5.67 \\
$\mathrm{GW} 22 \mathrm{Na}_{2} \mathrm{O} \cdot \mathrm{Al}_{2} \mathrm{O}_{3}$ & $30-47$ & $>47$ \\
$\mathrm{GW} \_\mathrm{Na}_{2} \mathrm{CO}_{3}$ & 4.5 & 6.33 \\
\hline
\end{tabular}

$\mathrm{NaOH}$ activation. $2 \mathrm{Na}_{2} \mathrm{O} \cdot \mathrm{Al}_{2} \mathrm{O}_{3}$ delayed the final setting time until $12 \mathrm{~h}$, and for $\mathrm{Na}_{2} \mathrm{CO}_{3}$ activation, final setting was achieved only after $30 \mathrm{~h}$ of curing.

In contrast, for glass wool the fastest final setting times were achieved by using $\mathrm{Na}_{2} \mathrm{CO}_{3}$ and $\mathrm{Na}_{2} \mathrm{O} \cdot 2 \mathrm{SiO}_{2}$ activators. With $2 \mathrm{Na}_{2} \mathrm{O} \cdot \mathrm{Al}_{2} \mathrm{O}_{3}$ activation of glass wool, final setting was not achieved within two days. During the setting time measurements, it was observed that $\mathrm{GW} \_2 \mathrm{Na}_{2} \mathrm{O} \cdot \mathrm{Al}_{2} \mathrm{O}_{3}$ sample had an uneven setting. The penetration depth of the Vicat needle into the paste did not decrease steadily, and there seemed to be areas in the sample with more progressed setting than in other areas. Thus, for the initial setting time, a period is reported.

b. Compressive strength development

The development of compressive strength of the alkali-activated stone wool samples follows the trend observed with setting times (Fig. 1). Activation of stone wool by $\mathrm{NaOH}$ resulted in high early strength (20 MPa after 1 day), which is in line with the fast setting (Table 3). Also, $\mathrm{Na}_{2} \mathrm{O} \cdot 2 \mathrm{SiO}_{2}$ produced high early strength (26 MPa), again consistent with the setting time, but the 28-day compressive strength (38 MPa) falls below that reached by $\mathrm{NaOH}$ activation. For the $2 \mathrm{Na}_{2} \mathrm{O} \cdot \mathrm{Al}_{2} \mathrm{O}_{3}$-activated stone wool sample, the strength development was slow compared to $\mathrm{NaOH}$ and $\mathrm{Na}_{2} \mathrm{O} \cdot 2 \mathrm{SiO}_{2}$-activated samples, as was the setting time, but the 28-day strength reached $59 \mathrm{MPa}$. From the four activators studied here, the lowest performance was demonstrated by $\mathrm{Na}_{2} \mathrm{CO}_{3}$-activated stone wool samples, with a final 28-day strength of only $1 \mathrm{MPa}$.

All activators studied produced good compressive strengths (48-70 MPa after 28 days of curing) for alkaliactivated glass wool pastes (Fig. 2). However, with the exception of $\mathrm{Na}_{2} \mathrm{O} \cdot 2 \mathrm{SiO}_{2}$, the compressive strength after 1 day was low $(<3 \mathrm{MPa})$ with all activators. Particularly, a delayed compressive strength development was observed for the $\mathrm{GW} \_2 \mathrm{Na}_{2} \mathrm{O} \cdot \mathrm{Al}_{2} \mathrm{O}_{3}$ as the sample was still soft after curing for 3 days, consistent with the setting time result. However, this mix reached over $60 \mathrm{MPa}$ after 28 days.

\section{c. Kinetics of reaction}

$\mathrm{NaOH}$ and $\mathrm{Na}_{2} \mathrm{O} \cdot 2 \mathrm{SiO}_{2}$ solutions provided a fast reaction with stone wool (Fig. 3), as measured by isothermal calorimetry, which is in line with the setting time and compressive strength results. With these activators, only one heat flow peak is observed, indicating a one-stage reaction. However, it is possible that the elevated temperature $\left(40{ }^{\circ} \mathrm{C}\right)$, under which the measurements were conducted, accelerated the reaction and consequently merged the two peaks 
Fig. 1 Unconfined compressive strength of alkali-activated stone wool paste samples between 1 and 28 days
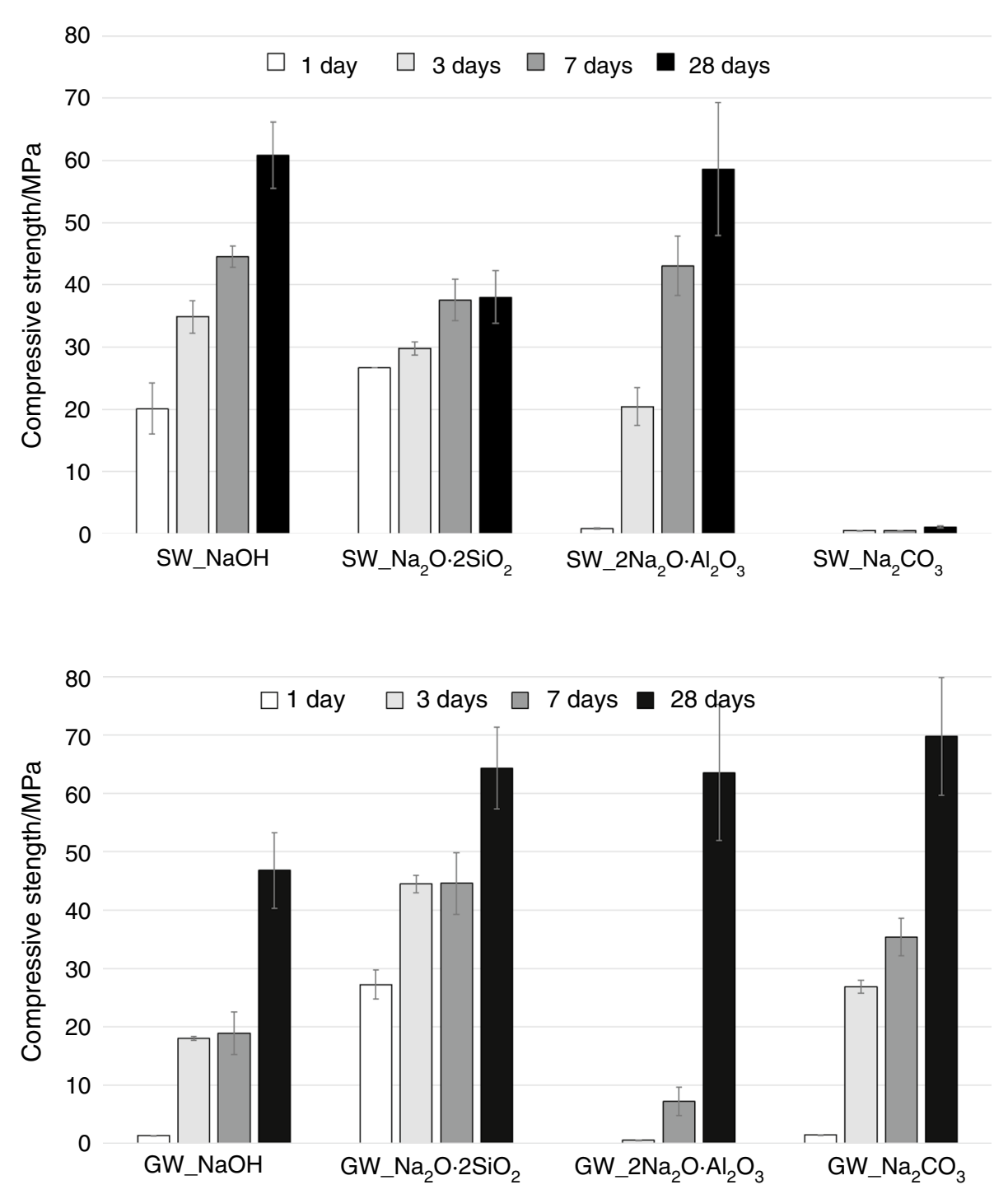

Fig. 2 Unconfined compressive strength of alkali-activated glass wool samples between 1 and 28 days (pre-induction peak and acceleration/deceleration peak) that are often observed in alkali-activated binders, e.g. those based on GGBFS [16, 17, 20, 21].

The heat release curve of stone wool activated by $\mathrm{Na}_{2} \mathrm{CO}_{3}$ exhibited a pre-induction period during the first $3 \mathrm{~h}$ of reaction, corresponding to wetting and dissolution of stone wool particles, and possibly also to the adsorption of some ions onto the surface of the stone wool particles. The pre-induction period was followed by a period of low heat release and reduced reaction. After $24 \mathrm{~h}$, an acceleration/deceleration peak is observed, which reaches its highest rate of heat release after $30 \mathrm{~h}$, corresponding to nucleation, growth, and precipitation of reaction products, as supported by the setting time results.

$2 \mathrm{Na}_{2} \mathrm{O} \cdot \mathrm{Al}_{2} \mathrm{O}_{3}$-activated stone wool exhibited a small preinduction peak, followed by a low heat release for $48 \mathrm{~h}$. It is likely that some nucleation, growth, and precipitation of reaction products occur during the first $12 \mathrm{~h}$ as the final setting was observed after this period. Between 48 and $96 \mathrm{~h}$, high heat release is observed, and the main reaction products must precipitate during this period as a high increase in compressive strength was determined (Fig. 1). The heat release curve has a shoulder on the left side of the peak and two small peaks on the top, which implies that the reaction has multiple stages.

The cumulative heat release data after $168 \mathrm{~h}$ (equal to 7 days) of the alkali-activated stone wool mixes (Fig. 3c) are consistent with the 7-day compressive strength results, i.e. high heat release corresponds to high compressive strength. The only exception is observed with $2 \mathrm{Na}_{2} \mathrm{O} \cdot \mathrm{Al}_{2} \mathrm{O}_{3}$ which has higher heat release than $\mathrm{NaOH}$, despite the samples having similar compressive strength.

The efficiency of an alkali activator is strongly influenced by the $\mathrm{pH}$, as this controls the initial dissolution of the precursor and the consequent precipitation reactions $[22,23]$. Here, the order of the $\mathrm{pH}$ of the activators 
Fig. 3 Heat of reaction of alkali-activated stone wool with different activators at $40{ }^{\circ} \mathrm{C}$, as measured by isothermal calorimetry. a Normalised heat flow of the first $8 \mathrm{~h}$ of reaction; $\mathbf{b}$ normalised heat flow of the first $150 \mathrm{~h}$ of reaction; $\mathbf{c}$ cumulative reaction heat
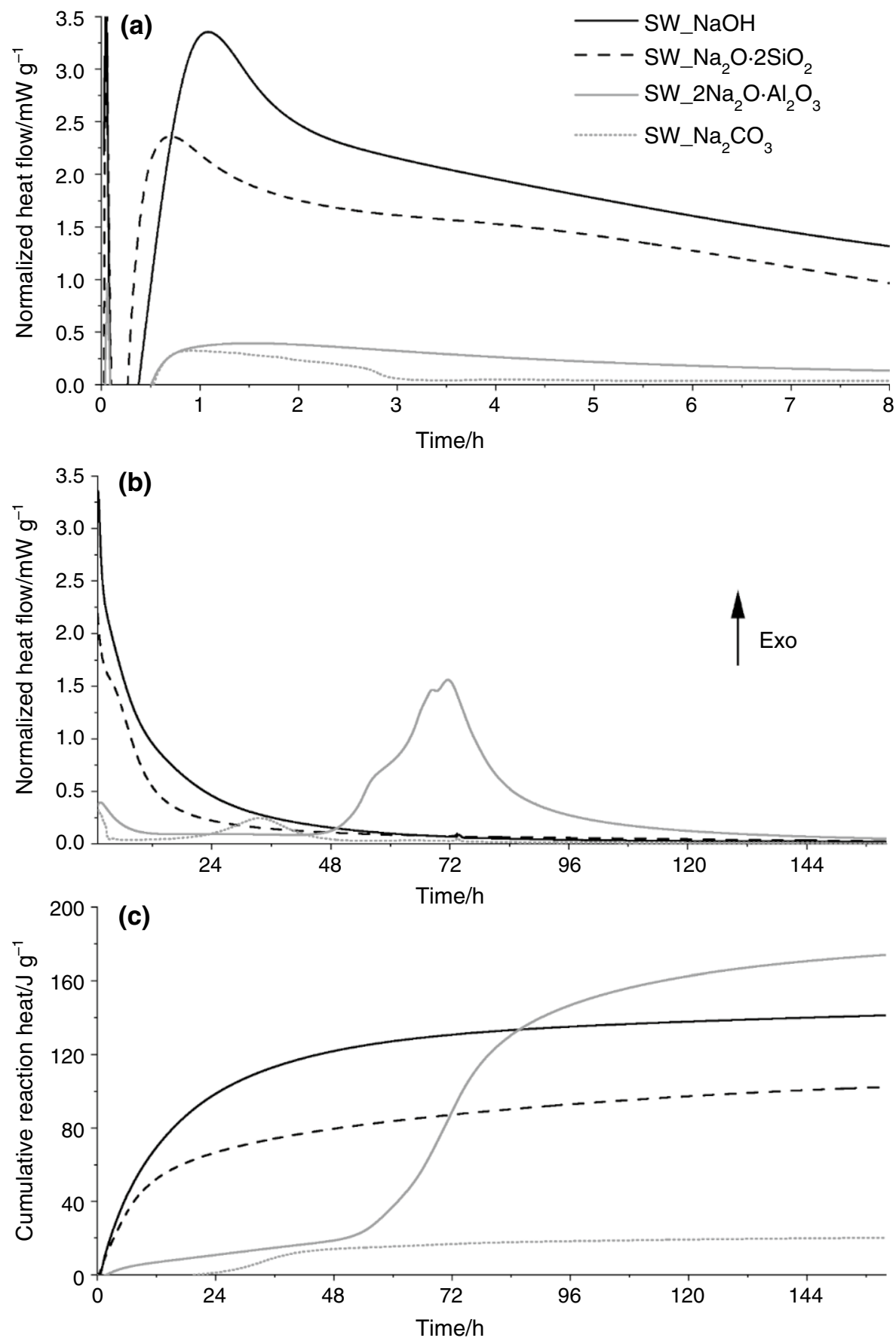

is $\mathrm{pH}_{\mathrm{NaOH}}>\mathrm{pH}_{2 \mathrm{Na} 2 \mathrm{O} \cdot \mathrm{Al} 2 \mathrm{O} 3}>\mathrm{pH}_{\mathrm{Na} 2 \mathrm{O} \cdot 2 \mathrm{SiO} 2}>\mathrm{pH}_{\mathrm{Na} 2 \mathrm{CO} 3}$, and reactivity approximately follows this order.

However, the anionic component of the activator also plays a major role in dissolution of the precursor and the hardening process. Particularly, silicate and aluminate species affect the binder gel formation. Silicate ions can react with dissolved $\mathrm{Ca}^{2+}$ and form dense $\mathrm{C}-(\mathrm{N}-) \mathrm{A}-\mathrm{S}-\mathrm{H}$ reaction products as observed in GGBFS-based binders [24] in the early stages of the hardening process. It therefore also promotes $\mathrm{Ca}$ dissolution from the precursor by maintaining a low Ca concentration in the solution through precipitation. In contrast, aluminate species in the solution may inhibit silica dissolution by adsorption to surface sites of silica [25, 26]. This prevents the approach of hydroxyl ions to the silica surface, rendering it inactive and significantly slowing down the dissolution process [27].

Based on previous studies with alkali-activated GGBFS, as a close point of comparison for stone wool, the rapid setting and high early strength observed with $\mathrm{NaOH}$ and $\mathrm{Na}_{2} \mathrm{O} \cdot 2 \mathrm{SiO}_{2}$ are due to the formation of $\mathrm{C}-(\mathrm{N}-) \mathrm{A}-\mathrm{S}-\mathrm{H}$ gel 
[24]. The formation of $\mathrm{C}-(\mathrm{N}-) \mathrm{A}-\mathrm{S}-\mathrm{H}$ gel in alkali-activated stone wool under similar mix design and curing conditions as used in this study was identified by diffractometric and spectroscopic techniques [18]. In contrast, $\mathrm{NaOH}$ activation produced quintinite $\left(\mathrm{Mg}_{4} \mathrm{Al}_{2}(\mathrm{OH})_{12} \mathrm{CO}_{3} \cdot 3 \mathrm{H}_{2} \mathrm{O}\right)$ in addition to $\mathrm{C}-(\mathrm{N}-) \mathrm{A}-\mathrm{S}-\mathrm{H}$ gel [18]. The precipitation of $\mathrm{Mg}-\mathrm{Al} \mathrm{LDH}$ phases is associated with the latter stage of the acceleration/deceleration peak in alkali-activated GGBFS [20], which could explain the higher heat release between 12 and $36 \mathrm{~h}$ compared to $\mathrm{Na}_{2} \mathrm{O} \cdot 2 \mathrm{SiO}_{2}$ activation.

Compared to alkali-activated GGBFS, the effect of the alkali activator on the compressive strengths of alkaliactivated stone wool follows a similar trend. High early strength is obtained with $\mathrm{Na}_{2} \mathrm{O} \cdot 2 \mathrm{SiO}_{2}$, followed by $\mathrm{NaOH}$, whereas $\mathrm{Na}_{2} \mathrm{CO}_{3}$ activators tend to give extremely slow strength development in low-Ca alkali-activated systems due to their lower alkalinity [28]. The reaction of GGBFS with $\mathrm{Na}_{2} \mathrm{CO}_{3}$ can be accelerated by the addition of LDHs in the reaction mixture [21]; thus, this approach could be feasible also with stone wool. Also a combination of activators, for example $\mathrm{NaOH}$ and $\mathrm{Na}_{2} \mathrm{O} \cdot 2 \mathrm{SiO}_{2}$ or $\mathrm{NaOH}$ and $\mathrm{Na}_{2} \mathrm{CO}_{3}$, warrants further investigation [22].

The setting times of the alkali-activated stone wool binders studied here are longer than determined for alkali-activated GGBFS when taking into account the curing temperature $\left(40{ }^{\circ} \mathrm{C}\right)$, assuming that the elevated temperature affects only the reaction rate. This may be due to the lower Ca content in stone wool compared to typical GGBFS (18 mass-\% vs. 40 mass-\%), as high Ca has been observed to cause faster setting. Slow setting under $\mathrm{Na}_{2} \mathrm{CO}_{3}$ activation has also been detected with GGBFS sources of varying compositions [29].

The heat release curves of alkali-activated glass wool pastes are presented in Fig. 4. A high early heat release peak is observed for samples activated with $\mathrm{Na}_{2} \mathrm{O} \cdot 2 \mathrm{SiO}_{2}$ and $\mathrm{Na}_{2} \mathrm{CO}_{3}$, implying rapid dissolution of glass wool, but also coagulation and precipitation of reaction products, as fast setting was determined for these samples (Table 3). $\mathrm{NaOH}$-activated glass wool has a wide heat release peak ranging from 1 to $36 \mathrm{~h}$, after which heat release continues with decreasing intensity for at least 10 days. The setting time of GW_NaOH was $10 \mathrm{~h}$, which would roughly match the highest point of the heat release peak.

The reaction of the GW_2 $\mathrm{Na}_{2} \mathrm{O} \cdot \mathrm{Al}_{2} \mathrm{O}_{3}$ mix occurs in two stages, with the initiation of the first stage not occurring until $72 \mathrm{~h}$ of curing, consistent with the long setting time and low early strength. After $72 \mathrm{~h}$, there is a constant rate of heat release lasting until $168 \mathrm{~h}$ of curing, again congruent with the low, but improved, compressive strength. The main heat release peak is observed between 168 and $216 \mathrm{~h}$, with the heat release continuing for more than 10 days. The late main precipitation reaction, depicted as a late main heat release peak for $\mathrm{GW} \_2 \mathrm{Na}_{2} \mathrm{O} \cdot \mathrm{Al}_{2} \mathrm{O}_{3}$, is in line with the high increase in compressive strength between 7 and 28 days (Fig. 2).

The cumulative heat release data (Fig. 4c) for the GW samples after $168 \mathrm{~h}$ (i.e. 7 days) are congruent with the 7-day compressive strength results for activation by $2 \mathrm{Na}_{2} \mathrm{O} \cdot \mathrm{Al}_{2} \mathrm{O}_{3}$ and $\mathrm{Na}_{2} \mathrm{CO}_{3}$, but not for $\mathrm{NaOH}$ and $\mathrm{Na}_{2} \mathrm{O} \cdot 2 \mathrm{SiO}_{2}$. This indicates that despite the greater extent of reaction (depicted by the higher cumulative heat release) by $\mathrm{NaOH}$, the binder gel formed is weaker compared to the reaction products of $\mathrm{Na}_{2} \mathrm{O} \cdot 2 \mathrm{SiO}_{2}$ activation. This is likely due to the extra silicate provided by the $\mathrm{Na}_{2} \mathrm{O} \cdot 2 \mathrm{SiO}_{2}$ activator, which can form sodium silicate gel with higher connectivity at a low extent of reaction of glass wool. The lower extent of reaction of glass wool with $\mathrm{Na}_{2} \mathrm{O} \cdot 2 \mathrm{SiO}_{2}$ after 7-day curing compared to reaction with $\mathrm{NaOH}$ is supported by the supplementary data provided in a previous study [18].

The chemistry of glass wool is very different from the chemistry of stone wool (Table 1), the main differences being in the $\mathrm{Si}, \mathrm{Ca}, \mathrm{Al}, \mathrm{Mg}$, and $\mathrm{Na}$ contents, which results in a different type of reaction pathway and binder gels. Previous studies showed that $\mathrm{NaOH}-$ and $\mathrm{Na}_{2} \mathrm{O} \cdot 2 \mathrm{SiO}_{2}$-activated glass wool binders consist of amorphous sodium silicate gel, with a partially Ca-substituted $\mathrm{N}-(\mathrm{A}-) \mathrm{S}-\mathrm{H}$ gel as an additional phase [18], whereas $3 \mathrm{Na}_{2} \mathrm{O} \cdot \mathrm{Al}_{2} \mathrm{O}_{3}$-activated glass wool contains amorphous and crystalline $\mathrm{N}-\mathrm{A}-\mathrm{S}-\mathrm{H}$ phases [7]. The short setting time, high early strength, and high early heat release of GW_NaOH, GW $\mathrm{Na}_{2} \mathrm{O} \cdot 2 \mathrm{SiO}_{2}$, and $\mathrm{GW} \_\mathrm{Na}_{2} \mathrm{CO}_{3}$ samples are likely due to precipitation of amorphous sodium silicate gel and $\mathrm{Ca}$-substituted $\mathrm{N}-(\mathrm{A}-) \mathrm{S}-\mathrm{H}$ gels [18]. In the case of $\mathrm{GW} \_2 \mathrm{Na}_{2} \mathrm{O} \cdot \mathrm{Al}_{2} \mathrm{O}_{3}$, the rate of reaction is slow. As explained earlier, aluminate species provided by the $2 \mathrm{Na}_{2} \mathrm{O} \cdot \mathrm{Al}_{2} \mathrm{O}_{3}$ may inhibit silica dissolution by $\mathrm{Al}_{2} \mathrm{O}_{3}$ adsorption on the surface sites of silica $[25,26]$, which is in line with the long setting time, low early strength, and long induction period of the $\mathrm{GW} \_2 \mathrm{Na}_{2} \mathrm{O} \cdot \mathrm{Al}_{2} \mathrm{O}_{3}$ sample. As the reaction progresses, a metastable high-Al $\mathrm{N}-\mathrm{A}-\mathrm{S}-\mathrm{H}$ gel is formed, which evolves with time into a higher-Si gel, responsible for the mechanical performance of the paste at longer curing times [30].

Among the activators studied here, $\mathrm{Na}_{2} \mathrm{CO}_{3}$ performed much better with glass wool than with stone wool. This could be due to the higher extent of dissolution and reactivity of glass wool in near-neutral $\mathrm{pH}$ conditions, as demonstrated by the high early heat release of $\mathrm{GW} \_\mathrm{Na}_{2} \mathrm{CO}_{3}$. A study by Campopiano et al. [31] showed that glass wool dissolves more rapidly at $\mathrm{pH} 7.4$ compared to stone wool due to its lower $\mathrm{Al}$ content. $\mathrm{Al}_{2} \mathrm{O}_{3}$ is essentially insoluble in water solutions at near-neutral $\mathrm{pH}$, and thus, stone wool with a high $\mathrm{Al}$ content will have lower solubility at less alkaline $\mathrm{pH}$ [32].

The environmental footprint is an important parameter when choosing the most appropriate activator for a specific binder mix. The lowest embodied $\mathrm{CO}_{2}$ emissions are 
Fig. 4 Heat of reaction of alkali-activated glass wool with different activators at $40{ }^{\circ} \mathrm{C}$, as measured by isothermal calorimetry. a Normalised heat flow of the first $12 \mathrm{~h}$ of reaction; $\mathbf{b}$ normalised heat flow of the first $240 \mathrm{~h}$ of reaction; c cumulative reaction heat
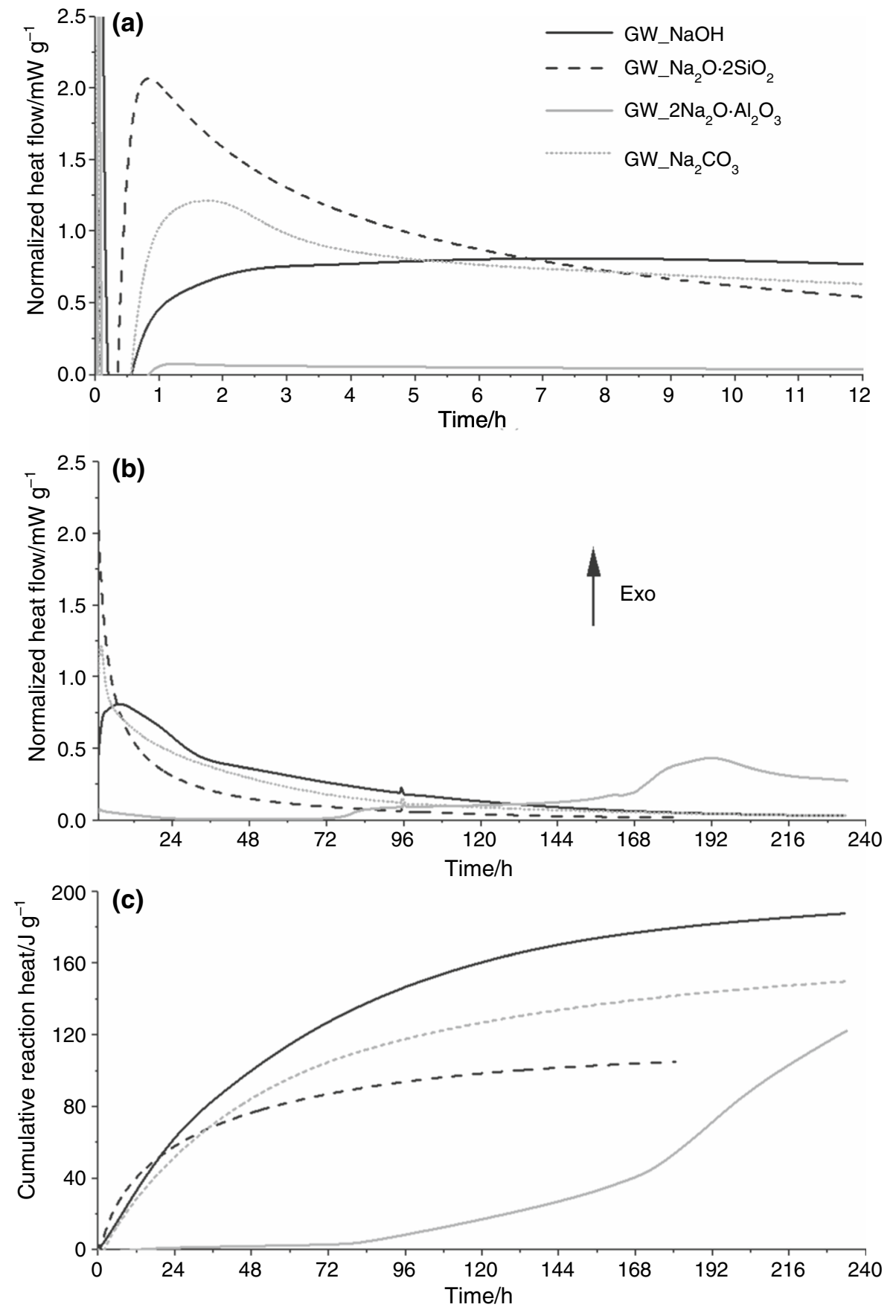

likely for $\mathrm{NaOH}$ and $\mathrm{Na}_{2} \mathrm{CO}_{3}$, particularly if sodium carbonate is obtained from natural mineral sources [1]. Also very low emissions could be obtained if waste Bayer liquor from the $\mathrm{Al}$ industry can be used as the $2 \mathrm{Na}_{2} \mathrm{O} \cdot \mathrm{Al}_{2} \mathrm{O}_{3}$ activator [33]. $\mathrm{Na}_{2} \mathrm{O} \cdot 2 \mathrm{SiO}_{2}$ usually yields the highest emissions [12], but could be acceptable if used in low dosages or derived from sustainable sources.

\section{Conclusions}

The nature of the activator plays a major part in the alkali activation process of mineral wools. Stone wool activated by sodium hydroxide or sodium silicate solution initiates a fast reaction, characterised by fast setting times, high 
early compressive strength, and high heat release during the first hours of reaction. In contrast, the hardening reaction of stone wool with sodium aluminate solution occurs only after 3 days of curing, but the reaction proceeds for a longer period, consequently yielding good compressive strength. The reaction rate and intensity of stone wool activation by $\mathrm{Na}_{2} \mathrm{CO}_{3}$ is low, appearing as long setting time and low compressive strength.

All activators studied produce high compressive strength (48-70 MPa) after 28 days of curing for glass wool. Activation with sodium silicate, sodium hydroxide, and sodium carbonate solutions initiated fast reaction, whereas with sodium aluminate solution, the main hardening reaction occurs only after 7 days of curing. The results presented here show that many activator types are suitable for mineral wools, but the nature of the activator plays a key role in the reaction kinetics. This enables several possible options for industrial operators depending on specific needs.

Acknowledgements Open access funding provided by University of Oulu including Oulu University Hospital. The authors gratefully acknowledge the financial support received from the project "Geodesign - Design geopolymers from mineral side streams" funded by Business Finland and companies Boliden Harjavalta Oy, Destaclean Oy, Fortum Power and Heat Oy, Paroc Group Oy, Saint-Gobain Finland Oy, and Suomen Erityisjäte Oy (Grant No. 1251/31/2015). The authors would like to thank Jani Kivelä for performing part of the experimental work as part of his bachelor thesis. The authors would like to thank Jarno Karvonen, Jani Österlund, Kaisu Ainassaari, and Elisa Wirkkala at the University of Oulu for their help with precursor analyses. Oday Hussain and Dan Geddes at the University of Sheffield are acknowledged for their help with calorimetry measurements. The authors thank Permakem AS for generously supplying the sodium silicate solution used in this investigation.

Open Access This article is licensed under a Creative Commons Attribution 4.0 International License, which permits use, sharing, adaptation, distribution and reproduction in any medium or format, as long as you give appropriate credit to the original author(s) and the source, provide a link to the Creative Commons licence, and indicate if changes were made. The images or other third party material in this article are included in the article's Creative Commons licence, unless indicated otherwise in a credit line to the material. If material is not included in the article's Creative Commons licence and your intended use is not permitted by statutory regulation or exceeds the permitted use, you will need to obtain permission directly from the copyright holder. To view a copy of this licence, visit http://creativecommons.org/licenses/by/4.0/.

\section{References}

1. Provis JL. Alkali-activated materials. Cem Concr Res. 2018;114:40-8.

2. Provis JL, van Deventer JSJ. Alkali Activated materials: state-ofthe-art report, RILEM TC 224-AAM. Dordrecht: Springer; 2014.
3. van Deventer JSJ, Provis JL, Duxson P. Technical and commercial progress in the adoption of geopolymer cement. Miner Eng. 2012;29:89-104.

4. Väntsi O, Kärki T. Mineral wool waste in Europe: a review of mineral wool waste quantity, quality, and current recycling methods. J Mater Cycles Waste Manag. 2013;16:62-72.

5. Nagy B, Simon TK, Nemes R. Effect of built-in mineral wool insulations durability on its thermal and mechanical performance. J Therm Anal Calorim. 2020;139:169-81.

6. Kinnunen P, Yliniemi J, Talling B, Illikainen M. Rockwool waste in fly ash geopolymer composites. J Mater Cycles Waste Manag. 2017;19:1220-7.

7. Yliniemi J, Kinnunen P, Karinkanta P, Illikainen M. Utilization of mineral wools as alkali-activated material precursor. Materials. 2016;9:312.

8. Nath SK, Mukherjee S, Maitra S, Kumar S. Kinetics study of geopolymerization of fly ash using isothermal conduction calorimetry. J Therm Anal Calorim. 2017;127:1953-61.

9. Nocuń-Wczelik W. Heat evolution in alkali activated synthetic slag-metakaolin mixtures. J Therm Anal Calorim. 2006;86:739-43.

10. Sun J, Chen Z. Effect of silicate modulus of water glass on the hydration of alkali-activated converter steel slag. J Therm Anal Calorim. 2019;138:47-56.

11. Alonso S, Palomo A. Calorimetric study of alkaline activation of calcium hydroxide-metakaolin solid mixtures. Cem Concr Res. 2001;31:25-30.

12. Habert G, Ouellet-Plamondon C. Recent update on the environmental impact of geopolymers. RILEM Tech Lett. 2016;1:17-23.

13. Provis JL. Chapter 1 Introduction and scope. Alkali Act Mater State--Art Rep RILEM TC 224-AAM. Dordrecht: Springer; 2014. p. $1-9$.

14. Wang S-D, Scrivener KL, Pratt PL. Factors affecting the strength of alkali-activated slag. Cem Concr Res. 1994;24:1033-43.

15. Fernández-Jiménez A, Puertas F. Setting of alkali-activated slag cement. Influence of activator nature. Adv Cem Res. 2001;13:115-21.

16. Ben Haha M, Lothenbach B, Le Saout G, Winnefeld F. Influence of slag chemistry on the hydration of alkali-activated blast-furnace slag_Part I: effect of MgO. Cem Concr Res. 2011;41:955-63.

17. Ben Haha M, Lothenbach B, Le Saout G, Winnefeld F. Influence of slag chemistry on the hydration of alkali-activated blast-furnace slag-Part II: effect of $\mathrm{Al}_{2} \mathrm{O}_{3}$. Cem Concr Res. 2012;42:74-83.

18. Yliniemi J, Walkley B, Provis JL, Kinnunen P, Illikainen M. Nanostructural evolution of alkali-activated mineral wools. Cem Concr Compos. 2020;106:103472.

19. Yliniemi JH, Laitinen O, Kinnunen P, Illikainen M. Pulverization of fibrous mineral wool waste. J Mater Cycles Waste Manag. 2018;20:1248-56.

20. Criado M, Walkley B, Ke X, Provis JL, Bernal SA. Slag and activator chemistry control the reaction kinetics of sodium metasilicate-activated slag cements. Sustainability. 2018;10:4709.

21. Ke X, Bernal SA, Provis JL. Controlling the reaction kinetics of sodium carbonate-activated slag cements using calcined layered double hydroxides. Cem Concr Res. 2016;81:24-37.

22. Fernández-Jiménez A, Puertas F. Effect of activator mix on the hydration and strength behaviour of alkali-activated slag cements. Adv Cem Res. 2003;15:129-36.

23. Shi C, Day RL. Selectivity of alkaline activators for the activation of slags. Cem Concr Aggreg. 1996;18:8-14.

24. Fernández-Jiménez A, Puertas F, Sobrados I, Sanz J. Structure of calcium silicate hydrates formed in alkaline-activated slag: influence of the type of alkaline activator. J Am Ceram Soc. 2003;86:1389-94. 
25. Abraitis PK, McGrail BP, Trivedi DP. The effects of silicic acid, aluminate ion activity and hydrosilicate gel development on the dissolution rate of a simulated British Magnox waste glass. Mater Res Soc Symp Proc. 1999;556:401.

26. Iler RK. Effect of adsorbed alumina on the solubility of amorphous silica in water. J Colloid Interface Sci. 1973;43:399-408.

27. Rees CA, Provis JL, Lukey GC, van Deventer JSJ. The mechanism of geopolymer gel formation investigated through seeded nucleation. Colloids Surf Physicochem Eng Asp. 2008;318:97-105.

28. Fernández-Jiménez A, Palomo A. Composition and microstructure of alkali activated fly ash binder: effect of the activator. Cem Concr Res. 2005;35:1984-92.

29. Bernal SA, Provis JL, Fernández-Jiménez A, Krivenko P, Kavalerova E, Palacios M, et al. Binder chemistry-high-calcium alkali-activated materials. Alkali Act Mater: State--Art Rep RILEM TC 224-AAM. Dordrecht: Springer; 2014. p. 59-91.

30. Fernández-Jiménez A, Palomo A, Sobrados I, Sanz J. The role played by the reactive alumina content in the alkaline activation of fly ashes. Microporous Mesoporous Mater. 2006;91:111-9.
31. Campopiano A, Cannizzaro A, Angelosanto F, Astolfi ML, Ramires D, Olori A, et al. Dissolution of glass wool, rock wool and alkaline earth silicate wool: Morphological and chemical changes in fibers. Regul Toxicol Pharmacol. 2014;70:393-406.

32. Guldberg M, Christensen VR, Perander M, Zoitos B, Koenig AR, Sebastian K. Measurement of in-vitro fibre dissolution rate at acidic pH. Ann Occup Hyg. 1998;42:233-43.

33. Jamieson E, McLellan B, van Riessen A, Nikraz H. Comparison of embodied energies of Ordinary Portland Cement with Bayerderived geopolymer products. J Clean Prod. 2015;99:112-8.

Publisher's Note Springer Nature remains neutral with regard to jurisdictional claims in published maps and institutional affiliations. 